\title{
Percutaneous Liver Biopsy in Infants: A Single Center Experience
}

\author{
Macchini Francesco ${ }^{1}$, Farris Giorgio ${ }^{1 *}$, Morandi Anna ${ }^{1}$, Gentilino Valerio ${ }^{1}$, Zanini Andrea ${ }^{1}$, Di Cesare Antonio ${ }^{1}$, Rossi \\ Giorgio $^{2}$, Nebbia Gabriella ${ }^{3}$ and Leva Ernesto ${ }^{1}$ \\ ${ }^{1}$ Department of Pediatric Surgery, Fondazione IRCCS Ca' Granda Ospedale Maggiore Policlinico, Milano, Italy
}

${ }^{2}$ General Surgery and Liver Transplantation Unit, Department of Pathophysiology and Transplantation, University of Milan and Fondazione IRCCS Ca' Granda, Ospedale Maggiore Policlinico, Milan, Italy

${ }^{3}$ Service of Paediatric Hepatology, Department of Paediatrics, Fondazione IRCCS Ca' Granda Ospedale Maggiore Policlinico, Milan, Italy

Received: May 12, 2017; Accepted: July 12, 2017; Published: September 13, 2017

*Corresponding author: Francesco Macchini, Department of Pediatric Surgery, Fondazione IRCCS Ca' Granda Ospedale Maggiore Policlinico, Via della Commenda 12, 20122, Milano, Italy, Tel: 0039 3356630049; Fax: 003902 55032154; Email: francesco.macchini@gmail.com

\begin{abstract}
Background: Percutaneous liver biopsy (PLB) is a procedure extensively used for diagnosis or treatment assessment of hepatic disease in childhood. The purpose of this study was to evaluate the safety and effectiveness of US-guided PLB in infancy.

Methods: Retrospective analysis of PLB performed in infants between January 2011 and December 2015 was conducted. All procedures were performed in inpatient infants, under general anaesthesia and US-guidance, with a disposable $16 \mathrm{G} \times 90 \mathrm{~mm}$ automated needle. The incidence of complications was evaluated. Postoperative coagulation studies were compared to preoperative ones.

Results: Twenty-four infants (62\% males; mean age: 89 days; mean weight: $5.7 \mathrm{~kg}$ ) underwent US-guided PLB. One biopsy for each patient was performed (mean number of passes: 1.7; mean number of samples: 1.2; biopsy core mean length: $1 \mathrm{~cm}$ ). The subcostal approach was preferred in 21 cases (87\%), the intercostal in $3(13 \%)$. Differential diagnosis included: biliary atresia (42\%); glycogen storage disease (21\%); total parenteral nutrition (TPN) cholestasis (12\%); neonatal hepatitis (9\%); follow-up for neonatal hemochromatosis post-chelation therapy $4 \%$. In 3 patients $(12 \%)$ a hepatic disease was excluded. None of the patients had minor or major complications. No deaths occurred. All biopsies provided enough liver for analysis. None of the infants had a biopsy repeated because of insufficient tissue.
\end{abstract}

Conclusion: US-PLB in infants is a simple, safe and effective diagnostic tool. Experienced physicians are advocated.

Keywords: Liver Biopsy; Infant; Bleeding; Neonatal Cholestasis

\section{Introduction}

Percutaneous liver biopsy (PLB) is a procedure extensively used for diagnosis or treatment assessment of hepatic disease in childhood [1-4].

Despite its well-established advantages, only few experiences in literature specifically evaluated the safety and morbidity of this procedure in infants younger than 1 year. Some evidence suggests that the risk of bleeding requiring transfusion may be higher in children than in adults [5-6].

The procedure can be done in different ways: a blind approach, relying on physical examination and anatomical landmarks to determine the site of puncture, or a guided ultrasound (US) approach that can be used to mark the optimal site or to obtain real-time sonographic images for optimal orientation, which has been advocated to reduce the risk of complications [7-10].

In fact, a lower frequency of complications, such as pneumothorax, bowel and gallbladder perforation, has been reported when US guidance is used [11-13].

The purpose of this study was to evaluate the safety and effectiveness of US-guided PLB in infancy in a single Center of Paediatric Surgery.

\section{Methods}

Medical records of all infants under 1 year of age who underwent an US-guided PLB between January 2011 and December 2015 were reviewed.

Data were retrospectively collected from patients' charts, laboratory results and pathology reports. The recorded information for analysis included demographics (age, sex, birth weight, gestational age and weight at surgery), clinical indication for biopsy, number of passes performed, number of cores obtained, adequacy of the samples for a correct diagnosis, surgical time, diagnosis.

Laboratory tests performed in the 48 hours previous to the biopsy included haemoglobin, platelet count, prothrombin time/International Normalized Ratio (INR), and activated partial thromboplastin time ratio (aPTT ratio). Typing and cross-matching for blood were routinely performed. If required, coagulation and hematologic abnormalities were corrected (parameters accepted: INR, $\leq 1.2$; aPTT ratio $\leq 1.2$ and platelets 
$>50.000)$.

All biopsies were done in the operatory room under general anaesthesia by the same team of experienced paediatric surgeons using sonographic guidance in inpatient infants. Informed consent was obtained from the parents. The setting of the operatory room was as follows: patient in supine decubitus, monitor at the head of the infant on the right side, surgeon and scrub nurse on the right side of the patient. A preoperative intravenous large-spectrum antibiotic profilaxis ( $50 \mathrm{mg} / \mathrm{kg}$ ceftriaxone i.v.) was administered for each infant.

A liver US was obtained to determine a safe needle pathway, avoiding interposing bowel, gallbladder, or major intraparenchymal hepatic vessels and ducts. The right lobe of the liver was sampled using a sterile technique through either a right subcostal mid-axillary approach as primary choice or through the last intercostal space on the right mid-axillary line in presence of interposed abdominal organs. The skin was scrubbed with $2 \%$ Clorexidine and subcutaneous tissues were infiltrated with Lidocaine $1 \%-0.5 \mathrm{~mL} / \mathrm{kg}$, and a small incision (2 mm) with a number 11 scalpel blade was made [14]. A disposable 16G x 90 $\mathrm{mm}$ automated needle was used in all procedures (Figure 1).

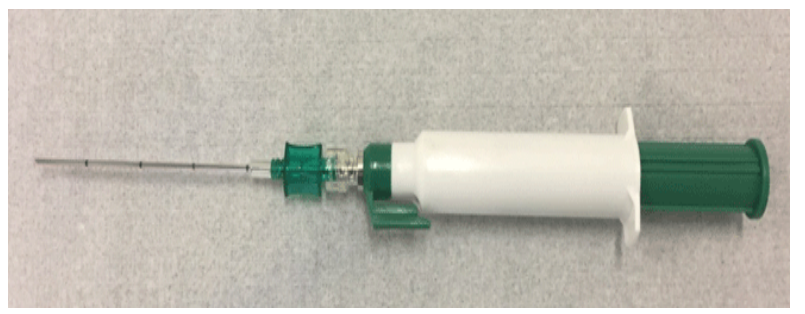

Figure 1: Disposable automated needle (16G x 90mm) used for percutaneous biopsies in infants

The biopsy needle was advanced under US guidance to the edge of the liver, fired during end inspiration and removed. Samples were obtained and sent for analysis. The number of passes performed through the liver and the adequacy of the biopsy sample were established at the operatory table by the surgeon performing the biopsy. In fact, the visual inspection of the hepatic fragment gives the evidence that enough histological material has been obtained [15]. As a consequence, if the surgeon was not satisfied with the size of the specimen, he could decide to perform another pass in the same session. Biopsies were considered "technically successful" if a sufficient liver sample was provided for analysis. Adequacy of the amount of tissue was assessed by reviewing the pathology reports. The length of the biopsy sample was also recorded.

After the procedure, compression was applied to the skin overlying the biopsy site to achieve satisfactory haemostasis. A right side decubitus was preferred to favour mechanical haemostasis.

All patients were kept in the hospital for observation at least 24 hours after the procedure. The protocol applied in our Center for post-PLB monitoring includes recording vital signs ( $\mathrm{SaO} 2$, heart rate, blood pressure and diuresis) every 15 minutes for 1 hour, every 30 minutes for the next 2 hours, and every hour for the next 3 hours. Haemoglobin checks by indwelling intravenous catheter are obtained 3 hours after biopsy. In fact it is described that $61 \%$ of complications occurs within the first 3 hours after the procedure $[16,17]$. Oral feeding is started in case of normal clinical and haemathological findings.

The incidence of complications related to the biopsy was evaluated. Complications were divided into minor or major according to the guidelines for imaging-guided percutaneous biopsy [16]. In particular, major complications were defined as death, haemorrhage requiring transfusion, need for catheter directed embolization or surgical intervention, haemobilia, bile leak, gallbladder perforation, haemothorax and pneumothorax. Minor complications were defined as pain requiring analgesia, asymptomatic subcapsular hematoma, fever and vomiting [11, $16,19,20]$.

Postoperative coagulation studies (haemoglobin; aPTT ratio; platelet count; and prothrombin time/ INR) were recorded and compared to preoperative ones.

The complication rate was evaluated with descriptive statistics. Comparison between haematological values before and after the procedures was performed using Student t-test. A p-value $<0.05$ was considered significant.

\section{Result}

In the studied period, among 62 children who underwent USguided PLB in our Institute, 24 (39\%) were infants younger than 1 year of age. Twenty-four biopsies were performed, one for each patient.

Fifteen $(62.5 \%)$ of the infants were boys. The mean age was 89 days (range 33-304 days; median 76 days) and the mean weight was $5.7 \mathrm{~kg}$ (range 3.1-9.7 kg; median $5.4 \mathrm{~kg}$ ). The mean gestational age at birth was 37.6 weeks (range, 26-42 weeks; median, 39 weeks) and the mean birth weight was $3.007 \mathrm{~kg}$ (range, 1.6-4.2 kg; median $3.150 \mathrm{~kg}$ ). All the biopsies were performed under general anaesthesia. All patients had a normal or corrected coagulation profile (INR $\leq 1.2$; aPTT ratio $\leq 1.2$ and platelets $>50,000$ ) before the procedure.

The clinical indication for biopsy was neonatal cholestatic liver disease [21].

All biopsies were successfully performed percutaneously with no need of conversion to open or laparoscopic surgery. The mean number of passes was 1.7 (range 1-6; median 1), the mean number of samples was 1.2 (range 1-2; median 1). The biopsy core mean length was $1 \mathrm{~cm}$ (range 0.4-1.7 cm; median $0.8 \mathrm{~cm}$ ). The subcostal approach was preferred in 21 cases (87\%), while the intercostal in $3(13 \%)$. None of the patients had minor or major complications. All biopsies provided enough liver or target tissue for analysis, giving a technical success rate of $100 \%$. None of the infants had a biopsy repeated because of inconclusive pathology or unsufficient tissue.

Differential diagnosis included: biliary atresia (10 cases, $42 \%$ ), glycogen storage disease (5 cases, $21 \%$ ), total parenteral nutrition (TPN) cholestasis (3 cases, 12\%) neonatal hepatitis ( 2 cases, 9\%) and follow-up for neonatal hemochromatosis 
postchelation therapy ( 1 case, 4\%) [22]. In 3 patients (12\%) a hepatic pathology was excluded.

The mean haemoglobin level was $11.7 \mathrm{~g} / \mathrm{dL}$ (range.8.9-15.9, $\mathrm{SD} \pm 2$ ) before the biopsy and 10.8 (range 6.7-17; SD \pm 2.5 ) after the biopsy $(\mathrm{p}=0.13)$. No significant difference in the platelet count, prothrombin time/International Normalized Ratio (INR), and aPTT ratio were recorded between pre- and post-operatively $(p=0.27 ; p=0.5$; and $p=0.5$; respectively). None of the infants required transfusion nor repeated US within the first 24 hours after the biopsy. No deaths occurred in our series.

\section{Discussion}

The acquisition of adequate liver tissue is mandatory for accurate diagnosis of liver disease and to correctly influence treatment decision. Even though in recent years non-invasive diagnostic methods, such as MRI, have been proposed as alternatives to liver sampling, liver biopsy remains an invaluable diagnostic tool especially in children and infants with atypical clinical features [3]. A 93\% accuracy rate has been described in infancy for PLB [23].

PLB is a procedure extensively used for diagnosis or treatment assessment of hepatic disease in childhood. Despite its well-established advantages, only few experiences in literature specifically evaluated the safety and morbidity of this procedure in infants younger than 1 year [24-26].

We retrospectively reviewed the experience of our Center to evaluate the feasibility, efficacy and safety of this procedure in patients less than 1 year of age.

Neither minor nor major complications were recorded in our series. These findings show better results compared to other experiences in literature, where the prevalence of complications after liver biopsy in the paediatric population varies from 2.8 to $5 \%[5]$.

One of the explaining factors may be related to the presence of dedicated experienced surgeons in our Institute. In fact, as suggested in literature, experience matters in reducing significant complications and liver biopsies should be performed only by specialists who have received appropriate instruction and supervision [25, 26]. Technical skill is related to the number of procedures performed. As a consequence, to reach an adequate amount of experience, it's crucial that the physician who does PLB in infants regularly performs this procedure also in the older paediatric population. The second and probably most significant factor is represented by the routinary use of US during the procedure. In fact, US may help in reducing the inadvertent puncture of major vascular and biliary structures as well as bowel. In our series, no pneumothorax, haemothorax, bile leak, bowel perforation, peritonitis, sepsis, pneumoperitoneum, or pneumoscrotum were observed. This is most likely related to the ability of US to directly visualize the trajectory of the needle in the liver and to avoid major structures such as the main bile ducts, bowel, gallbladder, and lungs. Lindor et al. published the results of a randomized trial comparing blind versus USguided PLB and showed a decreased rate of hospitalization, hypotension, and bleeding in the US-guided group [10]. Nobili et al., in a retrospective review of PLBs in children, also reported a significantly higher incidence of haemorrhagic complications and technical failure in unguided biopsies in comparison with sonographically guided biopsies [8]. Furthermore, several authors in the adult literature reported a significantly higher incidence of complications when sonographic guidance was not used (2.2-7.7\% vs. $0.5-2 \%)$ [3, 6, 12, 20, 29].

Riley TR et coll. report the need to change the site of biopsy in $15.1 \%$ of patients after US for the interposition of lung, gallbladder, vessels, ascites or colon [30].

Actually, US-guided PLB represents the technique of choice in the paediatric age [31]. In childhood, US are preferred to CT guided biopsy because US provide real time imaging, with absence of ionizing radiations, portability and decreased costs.

Regarding the financial cost related to the addition of US to the procedure, Younossi et al. and Pasha et al. showed that the cumulative cost for all patients is less than the potential cost for treatment of major complications $[3,6]$.

As regards the site of the puncture, the subcostal approach may represent a further factor reducing the occurrence of complications. The subcostal approach was feasible in the majority of our infants (87\%). Through it, the needle is inserted in a longitudinal plane, parallel to the course of the main biliary and vascular structures, reducing the probability to hurt them compared to the perpendicular puncture of an intercostal approach. In fact, the sub-costal approach seems to have minor risks of complications as compared to the intercostal one [32]. The US probe is kept coaxially to the needle. Tilting the probe helps in following the progression of the needle inside the liver during the whole procedure. In this way the manoeuvre results safe, similarly to the "in plane" US insertion of central lines in children [33].

We therefore suggest following a parallel orientation of the puncture when possible also in those infants where a subcostal approach may not be applicable. Finally, the subcostal puncture may also facilitate the surgical approach in case of severe bleeding not responding to conservative treatments.

Because haemorrhage is the most common complication after US-guided liver biopsy, evaluating the patient's bleeding history, blood parameters, and coagulation profile is paramount. As regards the post-operative course, a strict cardio-respiratory, pressure and haematologic monitoring is mandatory. In the present series no significant differences in haemoglobin, platelet counts and prothrombin time/International Normalized Ratio (INR), and partial thromboplastin time were recorded before and after the procedure.

In our series, all samples provided sufficient liver tissue for analysis using the automated 16-gauge size needle. Samples of $0.4 \mathrm{~cm}$ seem sufficient to establish a precise diagnosis. Similar adequacy was shown by other groups performing US-guided percutaneous liver biopsies [11, 34, 35].

Apart from the effectiveness of the procedure, the automated needle appears practical in allowing for the performance of the procedure with a single hand, while keeping the US probe in the other hand. This represents some clear advantages. In particular, doing the procedure alone the physician can reach a better 
orientation of the probe, better ergonomics and, wrapping the probe in a sterile coating, better asepsis.

All patients of the studied population were admitted for at least 24 hours of clinical observation. This policy is taken in agreement with the position statement on outpatient percutaneous liver biopsy provided by the North American Society for Paediatric Gastroenterology and Nutrition (NASPGHAN) from 1996. In this review, NASPGHAN suggests that patients at early infancy are at significantly higher risk of a complication or poor outcome and are not considered candidates for outpatient percutaneous liver biopsy [5].

In conclusion, US-guided PLB using automated biopsy guns provides adequate samples for accurate diagnosis and is clinically effective in infants younger than 1 year. Despite the procedure is not risk free, we think that it could be part of the panel of cultural and technical surgical skills of adequately trained paediatric surgeons. Further, multicenter, prospective studies are necessary to better assess the risks of PLB in this age group.

\section{References}

1. Mogahed EA, Mansy YA, Al Hawi Y, El Sayed R, El-Raziky M, El Karaksy H. Blind percutaneus liver biopsy in infants and children: Comparison of safety and efficacy of percussion technique and ultrasound assisted technique. Arab Journal of Gastroenterology. 2016;17(4):168-175.

2. Cohen MB, A-Kader HH, Lambers D, Heubi JE. Complications of percutaneous liver biopsy in children. Gastroenterology. 1992;102(2):629-632.

3. Younossi ZM, Teran JC, Ganiats TG, Carey WD. Ultrasound-guided liver biopsy for parenchymal liver disease - an economical analysis. Dig Dis Sci. 1998;43(1):46-50.

4. Pietrobattista A, Fruwirth R, Natali G, Monti L, Devito R, Nobili V. Is juvenile liver biopsy unsafe? Putting an end to a common misapprehension. Pediatr Radiol. 2009;39(9):959-961. Doi: 10.1007/ s00247-009-1311-9

5. Fox VL, Cohen MB, Whitington PF, Colletti RB. Outpatient liver biopsy in children: a medical position statement of the North American Society for Pediatric Gastroenterology and Nutrition. J Pediatr Gastroenterol Nutr. 1996;23(3):213-216.

6. Honar N, Jooya P, Haghighat M, Imanieh MH, Dehghani SM, Zahmatkeshan $\mathrm{M}$, et al. Complications of blind versus ultrasoundguided percutaneuos liver biopsy in children. Arab J Gastroenterol. 2015;16(3-4):90-93. Doi: 10.1016/j.ajg.2015.09.009

7. Pasha T, Gabriel S, Therneau T, Dickson ER, Lindor KD. Costeffectiveness of ultrasound-guided liver biopsy. Hepatology. 1998;27(5):1220-1226.

8. Nobili V, Comparcola D, Sartorelli MR, Natali G, Monti L, Falappa P, et al Blind and ultrasound-guideed percutaneous liver biopsy in children Pediatr Radiol. 2003;33(11):772-775.

9. Amaral JG, Schwartz J, Chait P, Temple M, John P, Smith C, et al. Sonographically guided percutanoues liver biopsy in infants: a retrospective review. AJR. 2006;187(6):W644-W649.

10. Dezsőfi A, Baumann U, Dhawan A, Durmaz O, Fischler B, Hadzic N, et al. Liver biopsy in children: position paper of the ESPGHAN Hepatology Committee. ESPGHAN Hepatology Committee. J Pediatr Gastroenterol Nutr. 2015;60(3):408-420. Doi: 10.1097/MPG.0000000000000632
11. Rossi P, Sileri P, Gentileschi P, Sica GS, Forlini A, Stolfi VM, et al. Percutaneous liver biopsy using an ultrasound-guided subcostal route. Dig Dis Sci. 2001;46(1):128-132.

12. Lindor KD, Bru C, Jorgensen RA, Rakela J, Bordas JM, Gross JB, et al. The role of sonography and automatic-needle biopsy in outpatient percutaneous liver biopsy. Hepatology. 1996;23(5):1079-1083.

13. Caturelli E, Giacobbe A, Facciorusso D, Bisceglia M, Villani MR, Siena DA, et al. Percutaneous biopsy in diffuse liver disease: increasing diagnostic yield and decreasing complication rate by routine ultrasound assessment of puncture site. Am J Gastroenterol. 1996;91(7):1318-1321.

14. Sathiyamurthy S, Banerjee J, Godambe SV. Antiseptic use in the neonatal intensive care unit - a dilemma in clinical practice: An evidence based review. World J Clin Pediatr. 2016;5(2):159-171.

15. Sporea I, Popescu A, Sirli R. Why, who and how should perform liver biopsy in chronic liver diseases. World J Gastroenterol. 2008;14(21):3396-3402.

16. Zins M, Vilgrain V, Gayno S, Rolland Y, Arrivé L, Denninger MH, et al. US-guided percutaneous liver biopsy with plugging of the needle track: a prospective study in 72 high-risk patients. Radiology. 1992;184(3):841-843.

17. van Beek D, Funaki B. Hemorrhage as a Complication of Percutaneous Liver Biopsy. Semin Intervent Radiol. 2013;30(4): 413-416.

18. Cardella JF, Bakal CW, Bertino RE, Burke DR, Drooz A, Haskal Z, et al. Quality improvement guidelines for image-guided percutaneous biopsy in adults. J Vasc Interv Radiol. 2003;14(9 pt 2):S227-S230.

19. Papini E, Pacella CM, Rossi Z, Bizzarri G, Fabbrini R, Nardi F, et al. A randomized trial of ultrasound-guided anterior subcostal liver biopsy versus the conventional Menghini technique. J Hepatol. 1991;13(3):291-297.

20. Farrell RJ, Smiddy PF, Pilkington RM, Tobin AA, Mooney EE, Temperley IJ, et al. Guided versus blind liver biopsy for chronic hepatitis C: clinical benefits and costs. J Hepatol. 1999;30(4):580-587.

21. Fawaz R, Baumann U, Ekong U, Fischler B, Hadzic N, Mack CL, et al. Guideline for the Evaluation of Cholestatic Jaundice in Infants: Joint Recommendations of the North American Society for Pediatric Gastroenterology, Hepatology, and Nutrition (NASPGHAN) and the European Society for Pediatric Gastroenterology, Hepatology, and Nutrition (ESPGHAN). JPGN. 2017;64:154-168.

22. Flynn DM, Mohan N, McKiernan P, Beath S, Buckels J, Mayer D, et al. Progress in treatment and outcome for children with neonatal haemochromatosis. Arch Dis Child Fetal Neonatal. 2003;88(2):F124127.

23. McKiernan PJ. Neonatal cholastasis. Semin Neonatol. 2002;7(2):153165.

24. Lichtman S, Guzman C, Moore D, Weber JL, Roberts EA. Morbidity after percutaneous liver biopsy. Arch Dis Child. 1987;62(9):901-904.

25. Amaral JG, Schwartz J, Chait P, Temple M, John P, Smith C, et al. Sonographically Guided Percutaneous Liver Biopsy in Infants: A Retrospective Review. AJR Am J Roentgenol. 2006;187(6):W644-W649.

26. Azzam RK, Alonso EM, Emerick KM, Whitington PF. Safety of Percutaneous Liver Biopsy in Infants Less than Three Months Old. J Pediatr Gastroenterol Nutr. 2005;41(5):639-643.

27. Chevallier P, Ruitort F, Denys A, Staccini P, Saint-Paul MC, Ouzan D, et al. Influence of operator experience on performance of ultrasoundguided percutaneous liver biopsy. Eur Radiol. 2004;14(11):2086- 
2091.

28. van der Poorten D, Kwok A, Lam T, Ridley L, Jones DB, Ngu MC, et al. Twenty-year audit of percutaneous liver biopsy in a major Australian teaching hospital. Intern Med J. 2006;36(11):692-629.

29. Cadranel JF, Rufat P, Degos F. Practices of liver biopsy in France: results of a prospective nationwide survey. For the Group of Epidemiology of the French Association for the Study of the Liver (AFEF). Hepatology. 2000;32(3):477-481.

30. Riley TR 3rd. How often does ultrasound marking change the liver biopsy site? Am J Gastroenterol. 1999;94(11):3320-3322.

31. Matos H, Noruegas MJ, Gonçalves I, Sanches C. Effectiveness and safety of ultrasound-guided percutaneous liver biopsy in children. Pediatric Radiol. 2012;42(11):1322-1325.
32. McGill DB. Liver biopsy: when, how, by whom, and where? Curr Gastroenterol Rep. 2001;3(1):19-23.

33. Pittiruti M. Ultrasound guided central vascular access in neonates, infants and children. Curr Drug Targets. 2012;13(7):961-969.

34. Cholongitas E, Quaglia A, Samonakis D, Senzolo M, Triantos C, Patch D, et al. Transjugular liver biopsy: how good is it for accurate histological interpretation? Gut. 2006;55(12):1789-1794.

35. Bravo AA, Sheth SG, Chopra S. Liver biopsy. N Engl J Med. 2001;344:495500. 